\title{
Exploring the Role of Feedback on Trust for the Robots Used in Homes of the Elderly
}

\author{
Fahd Newaz \\ University of Oslo \\ Oslo, Norway \\ fbnewaz@student.matnat.uio.no \\ Diana Saplacan \\ University of Oslo \\ Oslo, Norway \\ diana.saplacan@ifi.uio.no
}

Permission to make digital or hard copies of part or all of this work for personal or classroom use is granted without fee provided that copies are not made or distributed for profit or commercial advantage and that copies bear this notice and the full citation on the first page. Copyrights for third-party components of this work must be honored. For all other uses, contact the Owner/Author.

NordiCHI'18, September 29-October 3, 2018, Oslo, Norway (C) 2018 Copyright held by the owner/author(s).

ACM ISBN 978-1-4503-6437-9/18/09.

https://doi.org/10.1145/3240167.3240248

\begin{abstract}
This paper explores the role of design and use of digital feedback mechanisms in domestic autonomous devices. We explore this in relation to elderly's trust towards robots. Specifically, the paper reflects on a case study conducted with various user groups using semiautonomous vacuum cleaning robots. We have included both young and old participants in the study to expand our understanding of the potential challenges encountered. The methods employed were observation and interviews. The data shows that depending on the information users are provided about the actions and functionality of a given device, their degree of trust towards the device can be influenced. Similarly, there is a relation between the degree of trust toward the technology and the users' willingness to use it. Bridging the gap between the degree of trust towards a technology, through feedback, can play a critical role in encouraging people to use and retain any given technology.
\end{abstract}

\section{Author Keywords}

Robot; human-robot interaction; trust; feedback;

vacuum cleaners; automation; autonomous devices. 


\section{ACM Classification Keywords}

H.5.m. Information interfaces and presentation (e.g., HCI): Miscellaneous; I.2.9. Robotics: Autonomous vehicles, Commercial Robots and Applications; H.1.2. User/Machine Systems: Human factors; H.5.2. User Interfaces: Interaction styles, User-centered design; J.7. Computers in Other Systems: Consumer products.

\section{Introduction}

The focus of this study stems from the fact that as advancements in information technology are occurring at an unprecedented rate, so is society's dependence on these technologies. Younger generations may easily use new technology, since they grew up with easy access and exposure to new technological artefacts. But this is often challenging for adults, especially older adults, to do the same. This may cause many individuals to refrain from using new technology. In many cases this creates barriers that prevent access to critical services such as healthcare.

In Norway, due to a growing elderly population, the gap between those in need of healthcare assistance, and the availability of such assistance is increasing [14]. Technology can be seen as one solution to reducing the gap, enabling better use of the available healthcare resources [19]. However, we also need to investigate the actual use of these technologies amongst those that are affected, i.e. the elderly [19]. Specifically, lack of trust towards modern technologies has been identified as a key barrier that can prevent technology use $[3,7,11$, 13]. In this contribution, we discuss how feedback can play an essential role in design and use. Thus, our research question is: How could the design of better feedback mechanisms help increase the old people's level of trust towards the modern technologies?

\section{Literature Review}

Trust

As with any technology or product, the adoption and use of robot technology depends on effective interaction between the user and the device [4]. When referring to complex human-machine systems, trust can be defined as "the extent to which a user is confident in, and willing to act on the basis of the recommendations, actions, and the decisions of a computer-based tool or decision aid" [10]. Parasuraman and Riley [13] discuss the 'disuse' and 'misuse' of automation, referring, respectively, to the underuse of-, and over-reliance on automation, naming trust as one of the main causes. Dzindolet et al. [5] also emphasize the importance of trust as a factor affecting the decision to utilize automated systems. However, as a user gets more familiar with a given system, trust may be based on additional factors such as system performance, etiquette, interface usability and feedback. Designers need to consider the impact of their design decisions on user trust. This includes paying special attention to basic design principles such as visibility, feedback, affordance, consistency, and mapping [15]. We chose to focus further on the feedback design principle.

Feedback

Norman [12] defined feedback as one of the central design principles. Feedback can be defined as the results of the user's action [16, 18]. According to Liu and Hwang [9], feedback plays a pivotal role in increasing situational awareness, which in turn supports the development of trust. Additionally, Lee and Moray [7] put forward a hypothesis that a better understanding of how an automated system works will also increase trust in the system. "People rely on faulty automation when they are aware of automation imperfection" [2, p. 117], as they 


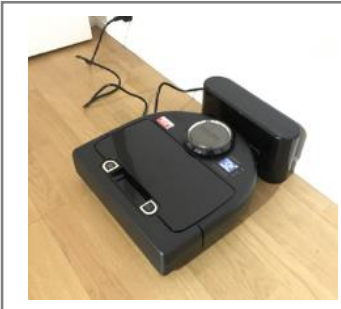

Figure 1: Neato BotVac, has LCD display, 2 buttons and an optional mobile app.

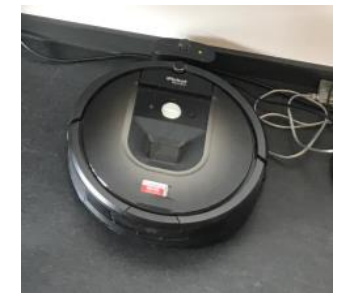

Figure 2: iRobot Roomba 980 , has 3 buttons and an optional mobile app.

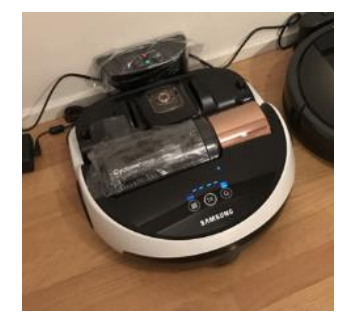

Figure 3: Samsung PowerBot, has 3 buttons and remote control. can then plan how they will work around any given imperfection. Thus, by providing suitable feedback, and making the users aware of their actions, a domestic robot could garner increased user trust. In the case of elderly users, additional care needs to be taken in order to understand how the feedback will be interpreted, keeping in mind factors such as physical and cognitive limitations (if any), as well as previous experience and exposure to technology. Desai et al. [4, p. 9] conclude that "in order to build systems which promote appropriate levels of trust, human-robot interaction designers will need to consider how to design both the robot's form and its interactions such that it provides feedback which will help the user understand the robot's capabilities and limitations.". Users must have an accurate conceptual model of how a system functions, based on a satisfactory understanding of the logic in its algorithms and its mechanics. Only then will they be able to trust, and comfortably use robots in their homes. This could be done through proper feedback mechanisms.

\section{Methods}

This study is qualitative and exploratory, aiming to gain a broader understanding about the use of robots in the home of elderly users. Specifically, we wanted to investigate what challenges the elderly encounter when they use semi-autonomous devices in their homes.

\section{Participants}

Our primary user group of interest is older adults ( $\geq 65$ years). Gathering data directly from this group of users is essential towards understanding their experiences, attitudes and emotions. Additionally, we have included younger participants that are more familiar with modern digital technology, in order to uncover higher level challenges regarding the use of the technology, and its weaknesses, that even expert users face. In total, 11 individuals, both males and females, of different ages, were included in the study so far. Six of the younger users were researchers involved in this study, with an average age of approximately 35 years. Five of the participants were elderly ( $\geq 65$ years).

\section{Data collection}

While methods such as observations and interviews provide significant data on the given research topic, Luck [9] discusses the importance of using artefacts to enrich the data collected through qualitative research methods, and "mediate understanding in design conversations.". We found it appropriate to turn to commercially available robots. This was practical, and at the same time also increased the relevance of the data to be collected, as many of the challenges regarding technology faced by elderly today, have to do with commercially available technology. Figures 1-3 show examples of the selected commercially available robots for this study.

Data Analysis

We have analyzed data through using open coding techniques, followed by grouping related phenomena into sub-categories, and further creating categories for related concepts [6].

\section{Findings and discussion}

All participants of this study were familiar with using a traditional vacuum cleaner, had to vacuum from time to time, but found the vacuuming difficult if their physical condition was problematic. However, one major difference with the robot vacuum cleaners was autonomy. While using a traditional vacuum cleaner, the user could decide when and where the vacuum cleaner would operate, and thus had full control. The element of 


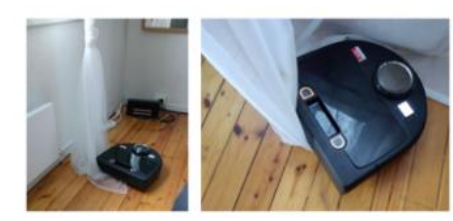

Figure 4: This image presents a breakdown situation where the Neato BotVac has navigated onto and gotten stuck on some curtains. autonomy related to the robot vacuum cleaners, however, introduced a sense of lack of control, as expressed by one participant, "It behaves as it wants to". While the elderly participants generally expressed lower levels of trust, the younger participants seemed to be quite optimistic, which interestingly corresponded to the level of previous exposure to technology for each of these two groups. This was evident from the initial fear of breakdown situations, expressed by the participants [17]. One such situation is presented in Figure 4.

In addition to expecting the technology to break down, lack of control seemed to influence the level of trust toward the technology. This was especially relevant with regard to the lack of feedback or getting improper feedback from the device. Comparing the experience to a traditional vacuum cleaner, one participant said, "On a normal vacuum cleaner, I press the button, and the vacuum cleaner is on. I point the vacuum cleaner where I want, and it vacuums there. On the robot, I press the start button, and I have no idea where it will go or what it will do. It has a mind of its own. I also don't know when it will be done cleaning." Another participant received the following feedback from the vacuum cleaner: Error 6 . The participant would not understand the meaning of the error. Such statements clearly demonstrate that the feedback from the technology is either lacking or is not appropriate, creating a sense of insecurity and doubt, on how the user should proceed. We believe minimizing these negative experiences, with the help of better design of feedback, can play a critical role in encouraging people to use and retain any given technology.

\section{Future work}

We have already found some relation between the level of trust and a user's positive attitude towards a technology, depending on the feedback the user receives from the device. However, further analysis is required in order to determine the role of digital feedback provided by the technology in use. Based on the challenges related to the use of robot vacuum cleaners that have been uncovered through the research so far, it may be possible to evaluate how different forms of feedback may assist in overcoming such challenges. At the same time, there may be other factors that also play an influential role in increasing user trust. Thus, in addition to collecting new data, we will analyze further the data. The aim will be to uncover new phenomena that may have been overlooked.

\section{Acknowledgements}

This work was part of the MECS project funded by the Norwegian Research Council IKTPluss Program (Grant agreement nr: 247697). We thank our project funders, partners, especially Kampen Omsorg Pluss, Project Manager and Prof. Jim Tørresen, supervisor Assoc. Prof. Jo Herstad, and colleagues: Trenton Schulz Rebekka Soma; and to ROBIN research group.

\section{References}

1. Monica Anderson and Andrew Perrin. 2017. Tech Adoption Climbs Among Older Adults. Retrieved April 25, 2018 from

http://www.pewinternet.org/2017/05/17/techadoption-climbs-among-older-adults/

2. Hasmik Atoyan, Jean-Rémi Duquet, and Jean-Marc Robert. 2006. Trust in new decision aid systems. In Proceedings of the 18th Conference on I'Interaction Homme-Machine (IHM '06). ACM, New York, NY, USA, 115-122. DOI=http://dx.doi.org/10.1145/1132736.1132751

3. Nasrine Bagheri and Greg A. Jamieson. 2004. Considering subjective trust and monitoring 
behavior in assessing automation-induced "complacency." In Human Performance, Situation Awareness, and Automation: Current Research and Trends, Dennis A. Vincenzi, Mustapha Mouloua, Peter A. Hancock (eds.). Lawrence Erlbaum Associates, Inc., Mahwah, NJ, 54-59.

4. Munjal Desai, Kristen Stubbs, Aaron Steinfeld, Holly Yanco. 2009. Creating Trustworthy Robots: Lessons and inspirations from automated systems. In Proceedings of the AISB Convention: New Frontiers in Human-Robot Interaction, Edinburgh, Scotland.

https://www.ri.cmu.edu/pub_files/2009/4/Desai_p aper.pdf

5. Mary T. Dzindolet, Scott A. Peterson, Regina A. Pomranky, Linda G. Pierce, Hall P. Beck. 2003. The role of trust in automation reliance. International Journal of Human-Computer Studies 58, 6: 697718.

6. Jonathan Lazar, Jinjuan Heidi Feng, Harry Hochheiser. 2010. Research Methods in HumanComputer Interaction. Chichester: John Wiley and Sons.

7. John D. Lee and Neville Moray. 1994. Trust, selfconfidence, and operators' adaptation to automation. Int. J. Hum. Comp. Stud. 40, 153184.

8. Cheng-Li Liu and Sheue-Ling Hwang. 2000. Evaluating the Effects of Situation Awareness and Trust With Robust Design in Automation.

International Journal of Cognitive Ergonomics, 4, 2: $125-144$.

9. Rachael Luck. 2007. Using artefacts to mediate understanding in design conversations. Building Research \& Information, 35:1, 28-41.

10. Maria Madsen and Shirley Gregor. 2000. Measuring human-computer trust. In Proceedings of 11th Australasian Conference on Information Systems (December 6-8, 2000), Brisbane.
11. Bonnie M. Muir. 1987. Trust between humans and machines, and the design of decision aids. Int. J. Man Mach. Stud. 27, 527-539.

12. Donald A. Norman. 1990. The design of everyday things. New York: Doubleday.

13. Raja Parasuraman and Victor Riley. 1997. Humans and automation: use, misuse, disuse, abuse. Human Factors: The Journal of the Human Factors and Ergonomics Society 39, 2: 230-253.

14. Jorun Ramm. 2013. Eldres bruk av helse- og omsorgstjenester. Retrieved October 3, 2017 from https://www.ssb.no/helse/artikler-ogpublikasjoner/_attachment/125965?_ts=13f8b5b6 898

15. Yvonne Rogers, Helen Sharp, Jennifer Preece. 2015. Interaction Design: Beyond humancomputer interaction. John Wiley \& Sons Ltd.

16. Diana Saplacan and Jo Herstad. 2017. A Quadratic Anthropocentric Perspective on Feedback - Using Proxemics as a Framework. In Proceedings of BritishHCI 2017. Sunderland, U.K. http://hci2017.bcs.org/wp-content/uploads/46.pdf

17. Diana Saplacan and Jo Herstad. 2018. Fear, Feedback, Familiarity... How are These Connected? - Can familiarity as a design concept applied to digital feedback reduce fear? In Proceedings of the ACHI 2018: The Eleventh International Conference on Advances in Computer-Human Interactions, 171-179. https://www.thinkmind.org/download_full.php?inst ance $=\mathrm{ACHI}+2018$

18. Ben Shneiderman. 1986. Designing the User Interface: Strategies for Effective Humancomputer Interaction. Boston, MA, USA: AddisonWesley Longman Publishing Co., Inc.

19. Jim Tørresen. 2016. Eldreomsorg med roboter. Retrieved October 1, 2017 from http://www.mn.uio.no/ifi/forskning/prosjekter/me cs/2016-09-23_dagens_naeringsliv_print.pdf 